\title{
Improvement in organophosphorus hydrolase activity of cell surface-engineered yeast strain using Flo1p anchor system
}

\author{
Takeshi Fukuda $\cdot$ Kouta Tsuchiyama $\cdot$ Hirokazu Makishima $\cdot$ \\ Katsumi Takayama Ashok Mulchandani - Kouichi Kuroda • \\ Mitsuyoshi Ueda $\cdot$ Shin-ichiro Suye
}

Received: 12 November 2009/Revised: 28 December 2009/Accepted: 6 January 2010/Published online: 29 January 2010

(C) The Author(s) 2010. This article is published with open access at Springerlink.com

\begin{abstract}
Organophosphorus hydrolase (OPH) hydrolyzes organophosphorus esters. We constructed the yeast-displayed OPH using Flo1p anchor system. In this system, the $N$-terminal region of the protein was fused to Flo1p and the fusion protein was displayed on the cell surface. Hydrolytic reactions with paraoxon were carried out during $24 \mathrm{~h}$ of incubation of $\mathrm{OPH}$-displaying cells at $30^{\circ} \mathrm{C}$. $p$-Nitrophenol produced in the reaction mixture was detected by HPLC. The strain with highest activity showed 8-fold greater $\mathrm{OPH}$ activity compared with cells engineered using glycosylphosphatidylinositol anchor system, and showed 20-fold greater activity
\end{abstract}

T. Fukuda $\cdot$ K. Tsuchiyama $\cdot$ H. Makishima

S. Suye $(\bowtie)$

Department of Applied Chemistry and Biotechnology, Graduate School of Engineering, University of Fukui,

3-9-1, Bunkyo, Fukui 910-8507, Japan

e-mail: suyeb10@u-fukui.ac.jp

K. Takayama

Department of Chemistry and Biology Engineering, Fukui National College of Technology, Geshi-cho, Sabae, Fukui 916-8507, Japan

A. Mulchandani

Department of Chemical and Environmental Engineering, University of California, Riverside, CA 92521, USA

K. Kuroda $\cdot$ M. Ueda

Division of Applied Life Sciences, Graduate School of Agriculture, Kyoto University, Kitashirakawa, Sakyo-ku, Kyoto 606-8502, Japan than Escherichia coli using the ice nucleation protein anchor system. These results indicate that Flo1p anchor system is suitable for display of $\mathrm{OPH}$ in the cell surface-expression systems.

Keywords Cell surface engineering · Flo1p anchor system · GPI anchor system . Organophosphorus hydrolase

\section{Introduction}

Organophosphorus compounds (OPs) such as pesticides, fungicides, and herbicides are highly toxic but are nevertheless used worldwide. The continued use of OPs increases the possibility that delayed cholinergic toxicity and neurotoxicity are induced (Tuovinen et al. 1994). Developed countries inspect imported agricultural food products for toxic OPs, and the growing public concern about their safety in modern agriculture has stimulated the development of methods for OPs detection. Current analytical techniques, such as chromatography, immunoassay, and the use of enzyme biosensors based on inhibition of cholinesterase activity, are highly sensitive but have disadvantages such as high cost or lengthy procedures (Cortada et al. 2009; Lee et al. 2003).

Organophosphorus hydrolase (OPH) effectively hydrolyzes OP esters, including pesticides, such as 
parathion (Tuovinen et al. 1994). We previously constructed a yeast strain that displayed OPH from Flavobacterium species; the cell surface-engineered yeast-displayed OPH using glycosylphosphatidylinositol (GPI) anchor system (Takayama et al. 2006). Details of this system are shown in Fig. 1a. Yeasts displaying OPH exhibited greater activity than Escherichia coli displaying $\mathrm{OPH}$ using the ice nucleation protein (INP) anchor system (Shimazu et al. 2001). However, it is possible that OPH activity might be suppressed in yeast strains when using GPI anchor system. Because the $\mathrm{OPH}$ active site is located near the $C$-terminus, the $3^{\prime}$-half of $\alpha$-agglutinin of the GPI anchor might be sterically hindered (Matsumoto et al. 2002). Therefore, we adopted an optimal anchor system for the location of the OPH active site.

In this study, yeasts displaying OPH using Flo1p anchor system were constructed. Flo1p is a lectin-like cell-wall protein in Saccharomyces cerevisiae. Detail of Flo1p are shown in Fig. 1b. Using Flo1p anchor system, a recombinant lipase having its active site near the $C$-terminus was displayed on the yeast and it showed higher activity than that obtained using GPI anchor system. Using Flo1p anchor system, we attempted to construct OPH-displaying yeasts that exhibited greater activity compared with that obtained using GPI anchor system.

\section{Materials and methods}

Strains and media

E. coli strain, DH5 $\alpha\left[F^{-}\right.$, endA1, hsdR17 $\left(r_{K}^{-}, m_{K}^{+}\right)$, supE44, thi-l, $\lambda^{-}$, recA1, gyrA96, AlacU169 ( $\varphi$ 80lacZ $\triangle M 15)]$, was used as a host cell for recombinant DNA manipulation. Saccharomyces cerevisiae MT8-1 (MATa, ade, his3, leu2, trp1, ura3) (Tajima et al. 1985), was used to display OPH from Flavobacterium species on its cell surface. LB medium with $50 \mu \mathrm{g}$ ampicillin $\mathrm{ml}^{-1}$ was used for bacterial growth and plasmid amplification. The yeast cells were grown in YPD medium $[1 \%(\mathrm{w} / \mathrm{v})$ yeast extract, $2 \%(\mathrm{w} / \mathrm{v})$ polypeptone, and $2 \%(\mathrm{w} / \mathrm{v})$ glucose]. Yeast recombinant transformants were selected on plates containing SD-W medium $[0.67 \%(\mathrm{w} / \mathrm{v})$ yeast nitrogen base without amino acids (Difco, MI, USA), 2\% (w/v) glucose, $0.002 \%(\mathrm{w} / \mathrm{v})$ adenine sulfate, $0.002 \%(\mathrm{w} / \mathrm{v})$ L-histidine$\mathrm{HCl}, 0.003 \%(\mathrm{w} / \mathrm{v})$ L-leucine, and $0.002 \%(\mathrm{w} / \mathrm{v})$ uracil].

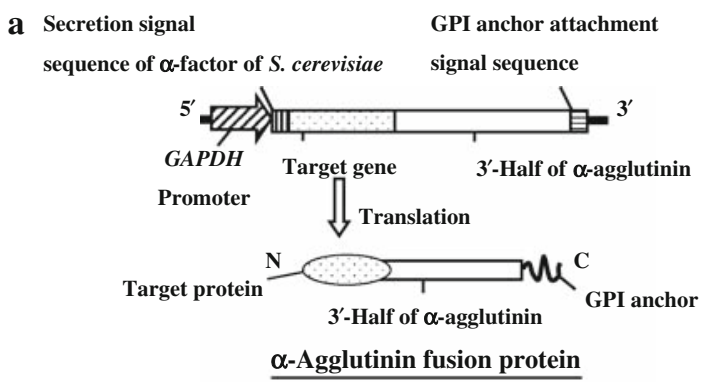

b

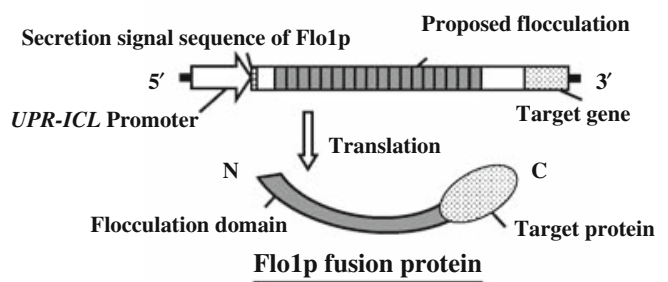

c

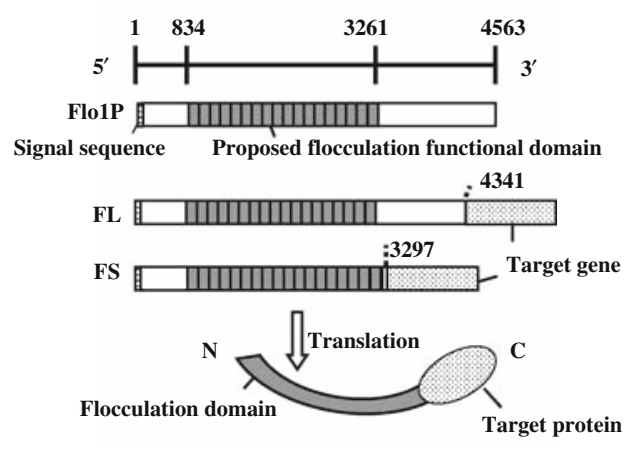

Flo1p (FL/FS) fusion protein

Fig. 1 The $\alpha$-agglutinin fusion gene and Flo1p fusion gene for display of protein on the yeast cell surface. a $\alpha$-Agglutinin fusion protein. The secretion signal sequence of $\alpha$-agglutinin and the GPI anchor attachment signal sequence are genetically fused to the $C$-terminal region of the target protein. b Flolp fusion protein. The $\mathrm{N}$-terminal regions of target proteins such as $\mathrm{OPH}$ are fused to the Flo1p flocculation functional domain. c Design of Flo1p (FL/FS) fusion gene for display of protein on the yeast cell surface

HEPES was added to the liquid SD-W medium at a concentration of $200 \mathrm{mM}$ (pH 7.0). Cell growth in the culture broth was measured based on absorbance at $600 \mathrm{~nm}$.

Construction of plasmids for cell surface display

Plasmids for OPH display using Flo1p anchor system were constructed as follows. The gene encoding $\mathrm{OPH}$ was amplified using PCR with pWM513 (Takayama et al. 2006) as the template (Fig. 2). Two forward 
primers were used. For the gene encoding $\mathrm{OPH}$, the forward primer was 5'-GGTAGATCTTCGATCGG CACAGG CCATCGGATCAAT-3' (BglII site, italic). To amplify the signal sequence domain of $\mathrm{OPH}$, we used the forward primer SigOPH-5': 5'-GGTAGATCTATGCAAACGAGAAGGGTTGTGCTCAAG-3' (BglII site, italic). In this sequence, the upstream region of OPH signal sequence is underlined. The OPH- $3^{\prime}$ reverse primer was $5^{\prime}$-ACTGCTCGAGCCTCCAG CCTTGTCATCGTCATCCTTGTAATCAGATCCA CCTGACGCCCGCAAGGTC GGTGACAA-3' (XhoI site, italic). pWIFS and pWIFL were the plasmid vectors used for expressing $\mathrm{OPH}$ on the yeast cell surface (Fig. 2). The FL gene comprised almost all the sequence of Flo1p and the FS gene consisted of part of Flo1p without 1,044 bp of $3^{\prime}$ downstream of the FL gene (Fig. 1c) (Matsumoto et al. 2002). The amplified fragment was digested and introduced in each plasmid vector (Fig. 2). The resulting plasmids were named pWIFSSigOPH, pWIFLSigOPH, pWIFSOPH, and pWIFLOPH (Fig. 2). OPH DNA was analyzed using a DNA sequencer (Applied Biosystems, Japan, Tokyo, Japan). The plasmids were transformed into $S$. cerevisiae MT8-1 by the lithium acetate method.

\section{Measurement of OPH activity}

The hydrolytic activities of OPH-displaying cells were assayed by measuring $p$-nitrophenol (PNP) produced during hydrolysis of Paraoxon (Sigma) as the substrate. Cells were precultured in $5 \mathrm{ml} \mathrm{SD-W}$ medium $[0.1 \mathrm{mM} \mathrm{CoCl} 2$ (Nacalai tesque, Kyoto, Japan)] for $24 \mathrm{~h}$ at $20^{\circ} \mathrm{C}$ and were further cultured for $75 \mathrm{~h}$. Cells were harvested by centrifugation at $3,000 \times g$ for $5 \mathrm{~min}$ at $25^{\circ} \mathrm{C}$ and washed three times with $50 \mathrm{mM}$ HEPES buffer ( $\mathrm{pH} 8.0$ ) containing $100 \mu \mathrm{M} \mathrm{CoCl}$. Washed cells were resuspended in $50 \mathrm{mM}$ HEPES buffer ( $\mathrm{pH}$ 8.0) containing $100 \mu \mathrm{M}$ $\mathrm{CoCl}_{2}$ and adjusted to $\mathrm{OD}_{600}=1$. An $\mathrm{OD}_{600}$ value of $1=0.313 \mathrm{mg}$ dry cells $/ \mathrm{ml}^{-1}$ (Horii et al. 2009). Next, $50 \mu \mathrm{l}$ of $20 \mathrm{mM}$ Paraoxon in methanol was added and reactions were carried out for $24 \mathrm{~h}$ at $30^{\circ} \mathrm{C}$. After incubation, cells were removed by filtration using a $0.22 \mu \mathrm{m}$ Ultrafree-MC filter unit (Millipore). PNP in the filtrated solution was detected by HPLC using Hitachi L-7100 and TSKgel for ODS80Ts $(75 \times 4.6 \mathrm{~mm}$ i.d.) (Tosoh, Tokyo, Japan) at $30^{\circ} \mathrm{C}$. The eluent was $90 \%(\mathrm{v} / \mathrm{v})$ acetonitrile in $50 \mathrm{mM}$ HEPES buffer $(\mathrm{pH} 8.5)$ at $0.5 \mathrm{ml} \mathrm{min}^{-1}$ at
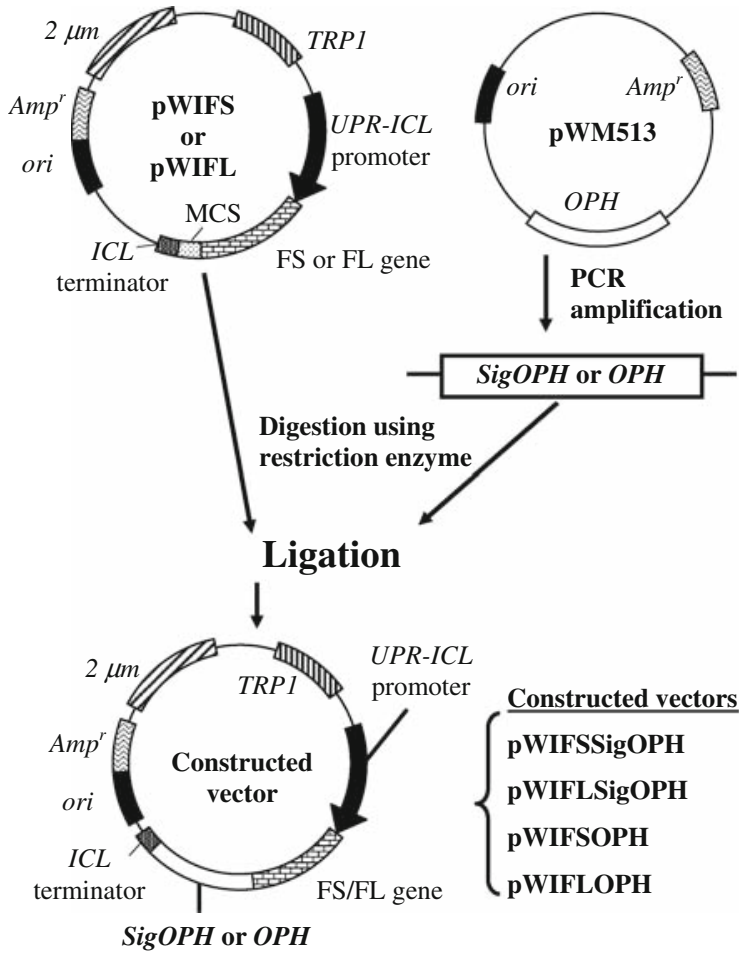

Fig. 2 Scheme for the construction of plasmids for display of $\mathrm{OPH}$ on the yeast cell surface using Flo1p anchor system. The gene encoding $\mathrm{OPH}$ is amplified by PCR with pWM513, as the template. pWIFS and pWIFL are the plasmid vectors for expressing the OPH on the yeast cell surface. The amplified fragment is digested and introduced in each plasmid vector. The resulting plasmids are named pWIFSSigOPH, pWIFLSigOPH, pWIFSOPH and pWIFLOPH

$30^{\circ} \mathrm{C}$ and the eluate was monitored at $415 \mathrm{~nm}$. The retention time of PNP was $12 \mathrm{~min}$. One enzyme unit is defined as the formation of $1 \mathrm{nmol}$ PNP per min per mg dry cells (Takayama et al. 2006).

\section{Results and discussion}

Effect of the anchor system on OPH activity

As shown in Fig. 3, MT8-1/pWIFLOPH using Flo1p anchor system showed 6-fold greater OPH activity compared with MT8-1/pWMSigOPH or MT8-1/ pWMOPH using GPI anchor system, indicating the effective display of OPH with an active site located near the $C$-terminus.

We investigated the effect of Flo1p length on $\mathrm{OPH}$ activity. The optimal whole cell activity of MT8-1/ pWIFSOPH was only 960 units/mg cell dry wt 


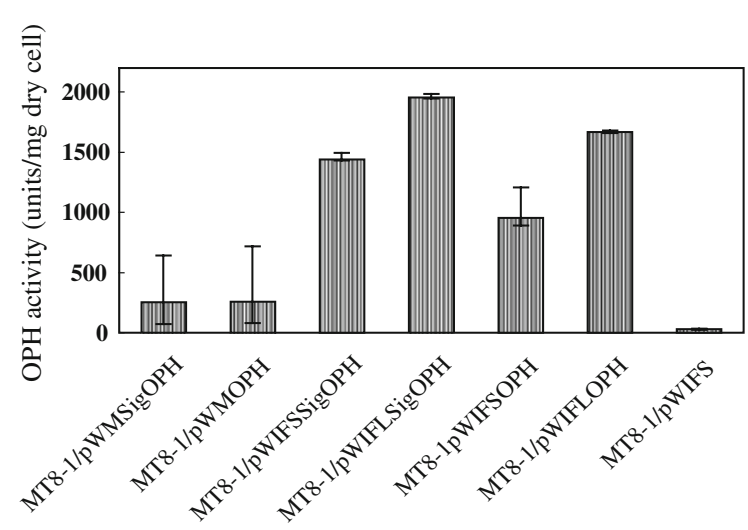

Fig. 3 Comparison of OPH activity of yeast cells transformed with various plasmids. The $y$ axis shows the OPH activity, which expressed as formation of $1 \mathrm{nmol}$ of PNP per min per mg dry cells (units/mg dry cell). The $x$ axis shows the strains. Strains MT8-1/pWIFSSigOPH, MT8-1/pWIFLSigOPH, MT8$1 / \mathrm{pWIFSOPH}$, and MT8-1/pWIFLOPH are constructed using Flo1p anchor system (present study). MT8-1/pWM-SigOPH and MT8-1/pWMOPH that were constructed previously (Takayama et al. 2006), are positive controls using GPI anchor system. MT8-1/pWIFS is a negative control using Flo1p anchor system, which was not inserted OPH gene to the vector. Data are averages based on three independent measurements

whereas, MT8-1/pWIFLOPH had 1,600 units/mg dry cell (Fig. 3). Matsumoto et al. (2002) demonstrated that the yeast cells displaying FL-anchor protein had higher flocculation ability than that of the FS-anchor protein and that the flocculation ability of the FL-anchor protein was sufficient to absorb on the cell surface. Therefore, a large amount of the FL-OPH fusion protein would be displayed stably on the cell surface compared with the FS-OPH fusion protein, and MT8-1/pWIFLOPH would exhibit high activity. This result shows that the $C$-terminal region of the FL-anchor protein (consisting of 3,297-4,341 bp of DNA sequence) was a significant domain for flocculation of the Flo1p-OPH fusion protein on the cell surface.

Effect of the OPH secretion signal on $\mathrm{OPH}$ activity

Next, the effect of the OPH secretion signal on OPH activity was investigated. MT8-1/pWIFSOPH and MT8-1/pWIFLOPH contained only the secretion signal sequence of Flo1p in the $5^{\prime}$-upstream region of Flo1p-OPH sequence in each transformed plasmid, whereas, MT8-1/pWIFSSigOPH and MT8-1/pWIFL-
SigOPH contained two secretion signal sequences for $\mathrm{OPH}$ in the $5^{\prime}$-upstream region of $\mathrm{OPH}$ and a secretion signal sequence for Flo1p in the $5^{\prime}$-upstream region of Flo1p in each transformed plasmid. MT8-1/pWIFSSigOPH showed high activity (1,440 units/mg dry cell) compared with MT8-1/pWIFSOPH (960 units/ mg dry cell) (Fig. 3). While the flocculation ability of the FS-anchor protein was insufficient, in contrast to the FL-anchor protein (Matsumoto et al. 2002), the function of the OPH secretion signal might contribute to the efficient expression of OPH, and would complement its activity. Furthermore, MT8-1/pWIFLSigOPH showed highest activity (1,920 units/mg dry cell). A synergy between the FL/FS anchor and the secretion signal of OPH would be occurred toward activity of $\mathrm{OPH}$ on the yeast cell surface.

\section{Conclusions}

We succeeded in displaying OPH on the yeast cell surface using Flo1p anchor system, which resulted in higher OPH activity than GPI anchor system. In particular, MT8-1/pWIFLSigOPH showed 8-fold higher OPH activity than MT8-1/pWMSigOPH or MT8-1/pWMOPH. Microbial biosensors for OPs have been recently developed using recombinant $E$. coli intracellularly expressing the OPH gene, but the response was slow because of the mass-transport limitation of substrates and products across the cell membrane (Ranina et al. 1996). Therefore, E. coli was engineered to express OPH on the cell surface and the INP anchor was used to improve OPH display on the surface of $E$. coli (Shimazu et al. 2001). In the present study, we constructed a biocatalyst for OPs detoxification and detection based on the yeastdisplayed OPH using Flolp anchor system. The $\mathrm{OPH}$ activity of this strain was about 20 -fold more efficient than that obtained with $E$. coli using the INP anchor system. The strains we used may not only be useful for the detoxification of OP nerve agents but also for the rapid detection of OPs. For example, the fluorescence intensity of GFP depends on $\mathrm{pH}$; GFP displayed on $E$. coli showed $65 \%$ attenuation in fluorescence for a $\mathrm{pH}$ change from 8 to 6 (Shi and $\mathrm{Su}$ 2001). To detect OPs by monitoring $\mathrm{pH}$ changes in the fluorescence of GFP based on the protons generated by the hydrolysis performed by $\mathrm{OPH}$, 
novel strains that co-display GFP with $\mathrm{OPH}$ on the yeast surface are now being developed.

Acknowledgments The authors are grateful to Prof. Akihiko Kondo of Kobe University for useful discussion and the gift of Flo1p anchor system.

Open Access This article is distributed under the terms of the Creative Commons Attribution Noncommercial License which permits any noncommercial use, distribution, and reproduction in any medium, provided the original author(s) and source are credited.

\section{References}

Cortada C, Vidal L, Tejada S, Romo A, Canals A (2009) Determination of organochlorine pesticides in complex matrices by single-drop microextraction coupled to gas chromatography-mass spectrometry. Anal Chim Acta 638: 29-35

Horii K, Adachi T, Tanino T, Tanaka T, Sahara H, Shibasaki S, Ogino C, Hata Y, Ueda M, Kondo A (2009) Evaluation of cell surface-displayed protein stability against simulated gastric fluid. Biotechnol Lett 31:1259-1264

Lee JK, Ahn KC, Stoutamre DW, Gee SJ, Hammock BD (2003) Development of an enzyme-linked immunosorbent assay for the detection of the organophosphorus insecticide acephate. J Agric Food Chem 51:3695-3703

Matsumoto T, Fukuda H, Ueda M, Tanaka A, Kondo A (2002) Construction of yeast strains with high cell surface lipase activity by using novel display systems based on the Flo1p flocculation functional domain. Appl Environ Microbiol 68:4517-4522

Ranina EI, Efremenco EN, Varfolomeyev SD, Simonian AL, Wild JR (1996) The development of a new biosensor based on recombinant $E$. coli for the direct detection of organophosphorus neurotoxins. Biosens Bioelectron 11:991-1000

Shi H, Su WW (2001) Display of green fluorescent protein on Escherichia coli cell surface. Enzym Microb Technol 28: 25-34

Shimazu M, Mulchandani A, Chen W (2001) Cell surface display of organophosphorus hydrolase using ice nucleation protein. Biotechnol Prog 17:76-80

Tajima M, Nogi Y, Fukasawa T (1985) Primary structure of the Saccharomyces cerevisiae GAL7 gene. Yeast 1:67-77

Takayama K, Suye S, Kuroda K, Ueda M, Kitaguchi T, Tsuchiyama K, Fukuda T, Chen W, Mulchandani A (2006) Surface display of organophosphorus hydrolase on Saccharomyces cerevisiae. Biotechnol Prog 22:939-943

Tuovinen K, Kalistekorhonen E, Raushel FM, Hänninen O (1994) Phosphotriesterase promising candidate for use in detoxification of organophosphates. Fundam Appl Toxicol 23:578-584 